\title{
Validity and sensitivity of instrumented postural and gait assessment using low-cost devices in Parkinson's disease
}

Ignacio Álvarez ${ }^{1,2+}$, Jorge Latorre ${ }^{3,4+}$, Miquel Aguilar ${ }^{1,2}$, Pau Pastor ${ }^{1,2+}$ and Roberto Llorens $s^{3,4^{*}+}$ (0)

\begin{abstract}
Background: Accurate assessment of balance and gait is necessary to monitor the clinical progress of Parkinson's disease (PD). Conventional clinical scales can be biased and have limited accuracy. Novel interactive devices are potentially useful to detect subtle posture or gait-related impairments.

Methods: Posturographic and single and dual-task gait assessments were performed to 54 individuals with PD and 43 healthy controls with the Wii Balance Board and the Kinect v2 and the, respectively. Individuals with PD were also assessed with the Tinetti Performance Oriented Mobility Assessment, the Functional Gait Assessment and the 10-m Walking Test. The influence of demographic and clinical variables on the performance in the instrumented posturographic and gait tests, the sensitivity of these tests to the clinical condition and phenotypes, and their convergent validity with clinical scales were investigated.
\end{abstract}

Results: Individuals with PD in H\&Y I and 1.5 stages showed similar performance to controls. The greatest differences in posture and gait were found between subjects in H\&Y II.5 and H\&Y I-I.5 stage, as well as controls. Dual-tasking enhanced the differences among all groups in gait parameters. Akinetic/rigid phenotype showed worse postural control and gait than other phenotypes. High significant correlations were found between the limits of stability and most of gait parameters with the clinical scales.

Conclusions: Low-cost devices showed potential to objectively quantify posture and gait in established PD $(H \& Y \geq I I)$. Dual-tasking gait evaluation was more sensitive to detect differences among PD stages and compared to controls than free gait. Gait and posture were more impaired in akinetic/rigid PD.

Keywords: Parkinson's disease, Gait, Posture, Kinect, Wii balance board

\section{Background}

Parkinson's disease (PD) is a neurodegenerative disease, characterized by motor impairments with particular impacts on posture and gait, leading to postural

\footnotetext{
${ }^{*}$ Correspondence: rllorens@i3b.upv.es

${ }^{\dagger}$ Ignacio Álvarez, Jorge Latorre, Pau Pastor and Roberto Llorens contributed equally to this work

${ }^{3}$ Neurorehabilitation and Brain Research Group, Instituto Interuniversitario de Investigación en Bioingeniería, Universitat Politècnica de València, Ciudad Politécnica de la Innovación-Building 8B-Access M-Floor 0, Camino de Vera s/n, 46022 Valencia, Spain Full list of author information is available at the end of the article
}

instability and falls [1]. Previous PD research has described an overall decline in gait associated with neurodegeneration. Although gait does not appear to differ significantly between PD patients and healthy controls during the early stages of $\mathrm{PD}$, including those categorized as Hoehn and Yahr (H\&Y) I-II.5 [2], worsening gait speeds are expected across all $\mathrm{H} \& \mathrm{Y}$ stages and become especially evident in patients during the moderate and severe stages, including those categorized as $H \& Y \geq I I .5$ [3]. In addition to an association with the time course of clinical symptoms, worsening spatiotemporal gait parameters have been identified original author(s) and the source, provide a link to the Creative Commons licence, and indicate if changes were made. The images or other third party material in this article are included in the article's Creative Commons licence, unless indicated otherwise in a credit line to the material. If material is not included in the article's Creative Commons licence and your intended use is not permitted by statutory regulation or exceeds the permitted use, you will need to obtain permission directly from the copyright holder. To view a copy of this licence, visit http://creativecommons.org/licenses/by/4.0/. The Creative Commons Public Domain Dedication waiver (http://creativeco mmons.org/publicdomain/zero/1.0/) applies to the data made available in this article, unless otherwise stated in a credit line to the data. 
in individuals with akinetic/rigid (AR)- or freezingPD phenotypes $[4,5]$. Research has also demonstrated that the performance of dual tasks has a significant and consistent negative effect on gait performance in PD patients, at different gait speeds and for different tasks [6], and dual-task associated gait evaluation can be used to distinguish individuals with de novo PD from healthy controls, which is not possible through the evaluation of regular walking [7]. Standardized clinical scales are commonly used to assess posture and gait in clinical settings, but their limited accuracy and intrinsic subjectivity may dramatically reduce their reliability [8]. To overcome these limitations, different instrumented tools, such as force plates and motion-tracking systems, have been developed for the accurate assessment of posture and gait, respectively $[9,10]$. However, instrumented systems can be time- and space-consuming and are often unaffordable for most clinics, limiting their widespread use. Recent low-cost interactive technologies have shown comparable accuracy to laboratory-grade instrumented systems while being portable and affordable [11-13].

Wearable sensors that embed accelerometers and gyroscopes have been widely used to investigate posture and gait in subjects with PD $[14,15]$. However, the accuracy of the assessment using wearable sensors depends on sensor location, sensor-to-segment alignment, and, frequently, on the number of sensors, which increases the total cost and obtrusiveness of the setting [16]. The Wii Balance Board (WBB) (Nintendo, Kyoto, Japan) and the Kinect for Windows v2, also known as Kinect v2 (Microsoft, Redmond, WA, USA), in contrast, potentially enable human motion tracking without the limitations of wearable sensors. The WBB is a portable and low-cost force platform that can estimate the center of pressure with comparable accuracy to that of laboratory-grade systems [17]. Preliminary research involving individuals with different neurological diseases, including PD, and different laboratory-grade systems has also shown that the WBB is a valid and feasible tool for the measurement of postural control and static balance during these conditions [1820]. The low-cost, infrared camera Kinect v2 enables the motion tracking of the main joints of the human body, without requiring wearable markers. The potential for the Kinect v2 to determine the spatiotemporal and kinematic variables associated with gait has been also investigated in patients with neurological diseases, with promising results [21-25]. Research has also shown good agreement between the Kinect and a laboratory-grade three-dimensional motion analysis system during measurements of movements of individuals with PD [26]. However, existing studies examining individuals with PD have included limited numbers of participants [21, 22, 25], which limits the ability to extrapolate results, or have only investigated specific parameters, without performing comprehensive postural or gait assessments [21, 22, 25].

We hypothesized that the WBB and the Kinect v2 can be used as sensitive and valid tools for the identification of postural and gait disturbances, which are present at PD onset in most individuals. The aim of this study was to determine the sensitivity of these tools for the evaluation of impairments associated with the clinical condition and phenotype of PD patients, and their convergent validity with conventional clinical scales.

\section{Methods \\ Participants}

A convenient sample of individuals with PD were recruited from the Movement Disorders Unit of the Hospital Universitari Mútua de Terrassa (Terrassa, Barcelona, Spain), from January 2017 to November 2018. Individuals were included if they met the UK Brain Bank criteria for PD [27], were categorized on the modified H\&Y scale as stages I-III [28], were able to walk $5 \mathrm{~m}$ without assistance or device, and did not present dyskinesia or significant cognitive impairments, as defined by scores $>18,21$, or 24 on the Mini-Mental State Examination, depending on the individual education level [29], at the time of evaluation.

Healthy participants, with no concurrent neurological or systemic disorders, postural or gait impairments, or lower limb prostheses, were primarily recruited among the relatives and caregivers of participants with PD.

Written informed consent was obtained from all participants, and the present study was approved by the Ethics Committee of the University Hospital Mútua de Terrassa.

\section{Instrumentation}

Postural control was assessed using a WBB-based posturography application, which included a modified clinical test of sensory interaction on balance (mCTSIB) and a limits of stability (LOS) test [19]. The MCTSIB investigated alterations in the sensory integration and processing, as a measure of sway, by analyzing variations in the center of pressure while barefoot subjects remained as still as possible, in a standing position, for $30 \mathrm{~s}$, under four different sensorial conditions: eyes opened and closed on the platform and eyes opened and closed on a piece of foam over the platform. The LOS test quantified the maximum displacement achievable for the center of pressure while maintaining contact between the soles of the feet and the platform, in eight directions, and the reaction time necessary to initiate the movement.

Spatiotemporal gait features were assessed with a Kinect v2-based gait analysis application [30], which required participants to walk towards the Kinect v2 at 
least three times, from a distance of $6 \mathrm{~m}$, and estimated the most widely-used spatiotemporal and kinematic gait parameters; toe kinematics were not assessed using this application due to poor reliability [22,31].

A WBB and a Kinect v2 were used to estimate the center of pressure of the participants and to retrieve the 3-dimensional body pose of participants, respectively. A conventional laptop was used to run both applications.

\section{Procedure}

All participants with PD underwent a complete neurological evaluation, including the collection of demographic and clinical data, and were categorized by neurologists (MA, PP) into tremor dominant (TD), akinetic/rigid (AR) or mixed (MX) phenotypes as described previously [32, 33] (Table 1). Individuals with PD were also assessed using a battery of clinical scales, including the Unified Parkinson's Disease Rating Scale (UPDRS) [34], the Neuropsychiatric Inventory Questionnaire [35], the NonMotor Symptoms Scale [36], the modified-Minnesota Impulsive Disorders Interview [37], the 39-Item Parkinson's Disease Questionnaire [38], the Tinetti Performance Oriented Mobility Assessment [8], the Functional Gait Assessment [8], and the 10-m Walking Test [39]. Finally, all participants, including those with PD and healthy subjects, were assessed by the instrumented posturography and gait analysis applications. For the dual-task condition, subjects were instructed to walk towards the camera while simultaneously counting backward from a number randomly picked between 60 and 110, either by ones, by twos (odd and even), by threes, or by sevens, according to the educational level and individual capabilities of each participant, which were assessed before the experiment. Subjects were allowed to rest between tests if needed.

All assessments occurred in a dedicated room, free of distractors, and were performed by the same experimenter. The laptop used to run the applications was placed on a table, at a height of $80 \mathrm{~cm}$. The Kinect v2 was placed on the table in front of the laptop, pointing towards the room. The WBB was situated on the floor, $1.5 \mathrm{~m}$ away from the table.

\section{Data analysis}

Participants with PD were categorized into three groups, according to their H\&Y scores: I-I.5, II, and II.5 [28]. Because only two participants were scored as H\&Y I.5, they were merged into the H\&Y I group. The mean value of each postural parameter was defined as the mean value of each subtest, to ensure the homogeneity of subjects' data.

Multiple regression analyses were performed to evaluate the influences of age, sex, education, height, weight, and disease duration on posturographic and gait measurements during the single-task condition. Demographic and clinical differences between groups were investigated using analysis of variance (ANOVA) and frequency analyses, applying Bonferroni and Cramer's $\mathrm{V}$ post hoc corrections to quantitative and qualitative variables, respectively. Student's t-tests and ANOVA analyses were also used to evaluate differences between all measures of postural control and gait, including (1) between controls and all individuals with PD; (2) between controls and the H\&Y I-I.5, II, and II.5 groups, separately; (3) among the H\&Y groups; and (4) among groups of participants with different phenotypes. Post hoc Bonferroni correction was applied to all ANOVA tests. The convergent validity of measurements made using instrumented posturography and gait analyses and those made using conventional scales was determined using Pearson's correlation analyses. The significance level was established at 95\% confidence.

\section{Results}

Participants

Fifty-four individuals with PD (11 individuals in stage I-I.5, 37 individuals in stage II, and 6 individuals in stage II.5) and 43 healthy controls participated in the study.

The three groups of participants with PD demonstrated significantly different scores for subparts II and III of the UPDRS and for the lower body sub-items of part III (Table 1). Significant differences were also found among these groups for disease duration and the scores on the Non-Motor Symptoms Scale, the Tinetti Performance Oriented Mobility Assessment, the Functional Gait Assessment, and the 10-m Walking Test. Other demographic and clinical varia bles showed no significant differences, supporting the existence of inter-group homogeneity. Phenotypes were similarly distributed among groups. Forty-four participants (81.4\%) were being treated with levodopa (Table 1).

Twenty-five healthy women (58\%) and 18 men (42\%), with a mean age of 67.84 years, participated in the study and completed the posturographic and gait assessments. All participants completed all the tests. Data from three healthy participants during the dual-task gait condition could not be retrieved and were not included in the analysis.

\section{Influence of demographic and clinical variables}

Regression analyses showed the statistically significant influences of age on the mean displacement during LOS $(\beta=-0.461 ; p=0.002)$, gait speed $(\beta=-0.446$; $\mathrm{p}=0.002)$, cadence $(\beta=0.384 ; \mathrm{p}=0.030)$, and stride time $(\beta=0.438 ; p=0.009)$, of height on gait speed $(\beta=0.465$; $\mathrm{p}=0.001)$ and stride length $(\beta=0.473 ; \mathrm{p}=0.002)$, and of weight on stride width $(\beta=0.592 ; \mathrm{p}<0.001)$. 
Table 1 Demographic and clinical characteristics of the participants with Parkinson's disease

\begin{tabular}{|c|c|c|c|}
\hline & H\&Y I-I.5 & $H \& Y I I$ & H\&Y II.5 \\
\hline Number of participants (n) & 11 & 37 & 6 \\
\hline Age (years) & $68.0 \pm 11.8$ & $68.7 \pm 10.2$ & $74.5 \pm 8.9$ \\
\hline \multicolumn{4}{|l|}{$\operatorname{Sex}(n, \%)$} \\
\hline Women & $2(18.2 \%)$ & $18(48.6 \%)$ & $4(66.7 \%)$ \\
\hline Men & $9(81.8 \%)$ & $19(51.4 \%)$ & $2(33.3 \%)$ \\
\hline Height (cm) & $170.2 \pm 9.4$ & $164.2 \pm 6.2$ & $162.2 \pm 8.3$ \\
\hline Weight (kg) & $79.3 \pm 15.4$ & $72.1 \pm 14.9$ & $75.0 \pm 11.7$ \\
\hline Education level (years) & $9.0 \pm 5.7$ & $9.0 \pm 4.3$ & $5.5 \pm 3.2$ \\
\hline Disease duration (years) & $3.8 \pm 2.1$ & $6.7 \pm 4.0$ & $8.9 \pm 5.6$ \\
\hline \multicolumn{4}{|l|}{ Phenotype (n, \%) } \\
\hline Tremor dominant & $6(54.5 \%)$ & $18(48.6 \%)$ & $3(50.0 \%)$ \\
\hline Akinetic/rigid & $2(18.2 \%)$ & $6(16.2 \%)$ & $2(33.3 \%)$ \\
\hline Mixed & $3(27.3 \%)$ & $13(35.1 \%)$ & $1(16.7 \%)$ \\
\hline Positive ioflupane 1123 injection test (n) & 5 out of $5(100 \%)$ & 12 out of $15(80 \%)$ & 2 out of $2(100 \%)$ \\
\hline \multicolumn{4}{|l|}{ Movement disorders* } \\
\hline \multicolumn{4}{|l|}{ Tremor type } \\
\hline Postural & $5(45.5 \%)$ & $9(24.3 \%)$ & $1(16.7 \%)$ \\
\hline Rest & $2(18.2 \%)$ & $6(16.2 \%)$ & $2(33.3 \%)$ \\
\hline Both & $3(27.3 \%)$ & $19(51.4 \%)$ & $2(33.3 \%)$ \\
\hline Freezing & 0 & $9(24.3 \%)$ & $1(16.7 \%)$ \\
\hline Festination & $2(18.2 \%)$ & $8(21.6 \%)$ & $2(33.3 \%)$ \\
\hline Dyskinesia & 0 & $6(16.2 \%)$ & 0 \\
\hline Fallers & $1(9.1 \%)$ & $8(21.6 \%)$ & $2(33.3 \%)$ \\
\hline Schwab \& England Activities of Daily Living Scale (100\%) (n) & $11(100 \%)$ & $24(64.9 \%)$ & $4(66.7 \%)$ \\
\hline REM Sleep Behavior Disorder (n) & $4(36.4 \%)$ & $21(56.8 \%)$ & $1(16.7 \%)$ \\
\hline \multicolumn{4}{|l|}{ Unified Parkinson's Disease Rating Scale } \\
\hline I. Mentation, Behavior And mood & $1.4 \pm 1.4$ & $2.5 \pm 2.3$ & $1.8 \pm 1.8$ \\
\hline II. Activities of daily living & $2.2 \pm 1.4^{2.3}$ & $7.4 \pm 4.2$ & $7.3 \pm 3.1$ \\
\hline III. Motor examination & $8.4 \pm 4.0^{2.3}$ & $18.7 \pm 7.5$ & $16.8 \pm 4.6$ \\
\hline III. Motor examination (lower body) & $2.2 \pm 1.5^{1}$ & $3.9 \pm 1.9$ & $4.6 \pm 1.5$ \\
\hline Mini Mental State Examination & $27.18 \pm 2.5$ & $27.18 \pm 2.5$ & $24.50 \pm 2.4$ \\
\hline modified Minnesota Impulsive Disorders Interview & $0.0 \pm 0.0$ & $2.05 \pm 4.7$ & $1.00 \pm 2.4$ \\
\hline 39-item Parkinson's Disease Questionnaire (\%) & $3.68 \pm 2.9$ & $14.07 \pm 15.3$ & $17.43 \pm 14.3$ \\
\hline Non-Motor Symptoms Scale & $13.36 \pm 12.6^{\mathrm{a}}$ & $34.86 \pm 24.1$ & $27.50 \pm 15.4$ \\
\hline \multicolumn{4}{|l|}{ Tinetti Performance Oriented Mobility Assessment } \\
\hline Total & $27.73 \pm 0.5^{d}$ & $26.68 \pm 1.6^{b}$ & $24.83 \pm 2.4$ \\
\hline Balance subscale & $15.73 \pm 0.5^{d}$ & $15.35 \pm 0.9^{b}$ & $14.17 \pm 1.3$ \\
\hline Gait subscale & $12.00 \pm 0.0^{b}$ & $11.32 \pm 0.9$ & $10.67 \pm 1.2$ \\
\hline Functional Gait Assessment & $27.91 \pm 2.5^{\mathrm{d}}$ & $25.68 \pm 3.0^{d}$ & $20.83 \pm 4.9$ \\
\hline 10-m Walking Test (s) & $4.50 \pm 0.7^{d}$ & $5.52 \pm 1.2$ & $6.68 \pm 2.0$ \\
\hline Levodopa currently treated (n, \%) & $3(27.3 \%)$ & $33(89.2 \%)$ & $6(100 \%)$ \\
\hline
\end{tabular}

Characteristics of participants with Parkinson's disease, grouped by their clinical progress. Data are presented as mean \pm SD or $n$ (\%). H\&Y: Hoehn \& Yahr

*Evaluated with the Unified Parkinson's Disease Rating Scale

a Significantly different from H\&YII $(p<0.05)$

b Significantly different from H\&Y II.5 $(p<0.05)$

c Significantly different from H\&Y II $(p<0.01)$

d Significantly different from H\&Y II.5 $(p<0.01)$ 


\section{Sensitivity to clinical conditions}

When the group containing all individuals with PD was analyzed, increased sway was observed compared with the healthy subject group, but no other statistically significant differences in the LOS or gait-related variables were found (Table 2). The in-depth analysis of participants with PD, when grouped by H\&Y stage, showed the progressive decline of postural control and gait with increasing H\&Y stages. The participants categorized as H\&Y II showed the worst performance for all postural and gait measurements among the three groups. In contrast, participants categorized as H\&Y I-I.5 not only showed better performance than individuals with more advanced pathological stages but also outperformed healthy subjects, including decreased sway and increased LOS and gait speed values (Table 2).

The additional cognitive demands required during dual-task execution resulted in deleterious effects for all gait measurements, in both healthy subjects and individuals with PD. Similar to the observed effects on regular walking when participants with PD were considered alone, all gait measurements during the dual-task condition were reduced for higher H\&Y stages. However, dual-tasking showed larger differences when groups of participants were compared with healthy subjects, and gait speed differences were detected among the groups of participants (Table 2).

\section{Sensitivity to phenotype}

Individuals with the AR phenotype showed decreased LOS values compared with those for participants with the TD and MX phenotypes. Specifically, individuals with the AR phenotype had lower mean maximum displacement values than those with the TD and MX phenotypes ( 7.07 vs 8.59 and $8.78 \mathrm{~cm}$, respectively; corrected $\mathrm{p}<0.05$, in both cases), and greater mean reaction times (1.73 vs 1.07 and $0.98 \mathrm{~s}$, respectively; corrected $\mathrm{p}<0.01$, in both cases). Although individuals with the AR phenotype showed consistently worse performance for all gait parameters, no other statistically significant differences in postural or gait measurements were found. Similarly, the effect of dual-task conditions on gait performance appeared to be more detrimental for patients with the AR phenotype, but no significant differences were found according to phenotype.

\section{Convergent validity}

Significant correlations were found between the mean displacement and mean reaction times for LOS and the conventional motor scales. No other significant correlations emerged (Table 3 ).

All instrumented gait parameters during the single-task condition, except for stride width, showed significant correlations with conventional clinical scales, with variable strengths. Among these correlations, the strongest interactions were found for the $10-\mathrm{m}$ Walking Test, which ranged from good to excellent. Independent of correlation strengths, the signs of the correlations were all coherent, and indicated that better performances on all postural and gait parameters were correlated with better performances on the clinical scales.

\section{Discussion}

In the present study, we investigated the use of the WBB and the Kinect v2 for the comprehensive analysis of posture and gait in $\mathrm{PD}$, focusing on the influence of demographic and clinical variables on postural- and gait-related parameters, the relationships between postural- and gait-related parameters, clinical conditions, and PD phenotype, and the convergent validity of these assessments with clinical scales. We found that postural and gait parameters were differentially influenced by age, height, and weight. Participants with PD showed impaired sway when compared with healthy controls, and a progressive decline in sway was associated with disease worsening. Patients with the AR phenotype had the worst performance among the groups. Different correlations with coherent and variable strengths were found between the posture and gait-related parameters assessed using the instrumented posturography applications and clinical scales.

The effects of demographical variables on posture and gait that were detected in our study are supported by the findings of previous studies, which highlighted age as an unavoidably deleterious factor [40-42], associated with cognitive, muscular, and structural changes. The heightrelated advantages in gait performance observed during our study have been also reported previously for individuals in similar age ranges as our participants, although this association appears to lose relevance beyond 80 years of age [43]. Similarly, previous studies have identified weight as a factor that influences stride performance [44], which supports the results found in our study.

The increased sway detected during advanced pathological stages has been repeatedly reported [45-47] and is supported by a recent review, which identified this feature as one of the five primary control systems, together with the LOS [48]. Reduced LOS has also been previously described for PD patients [49] and has been associated with an increased risk of falling [50,51]. The postural assessments performed during our study also demonstrated reduced LOS in participants with PD, which increased with disease progression, but failed to reveal statistical significant differences between PD patients and healthy controls, likely due to the limited number of participants in H\&Y stages $>$ II. The differences found during 


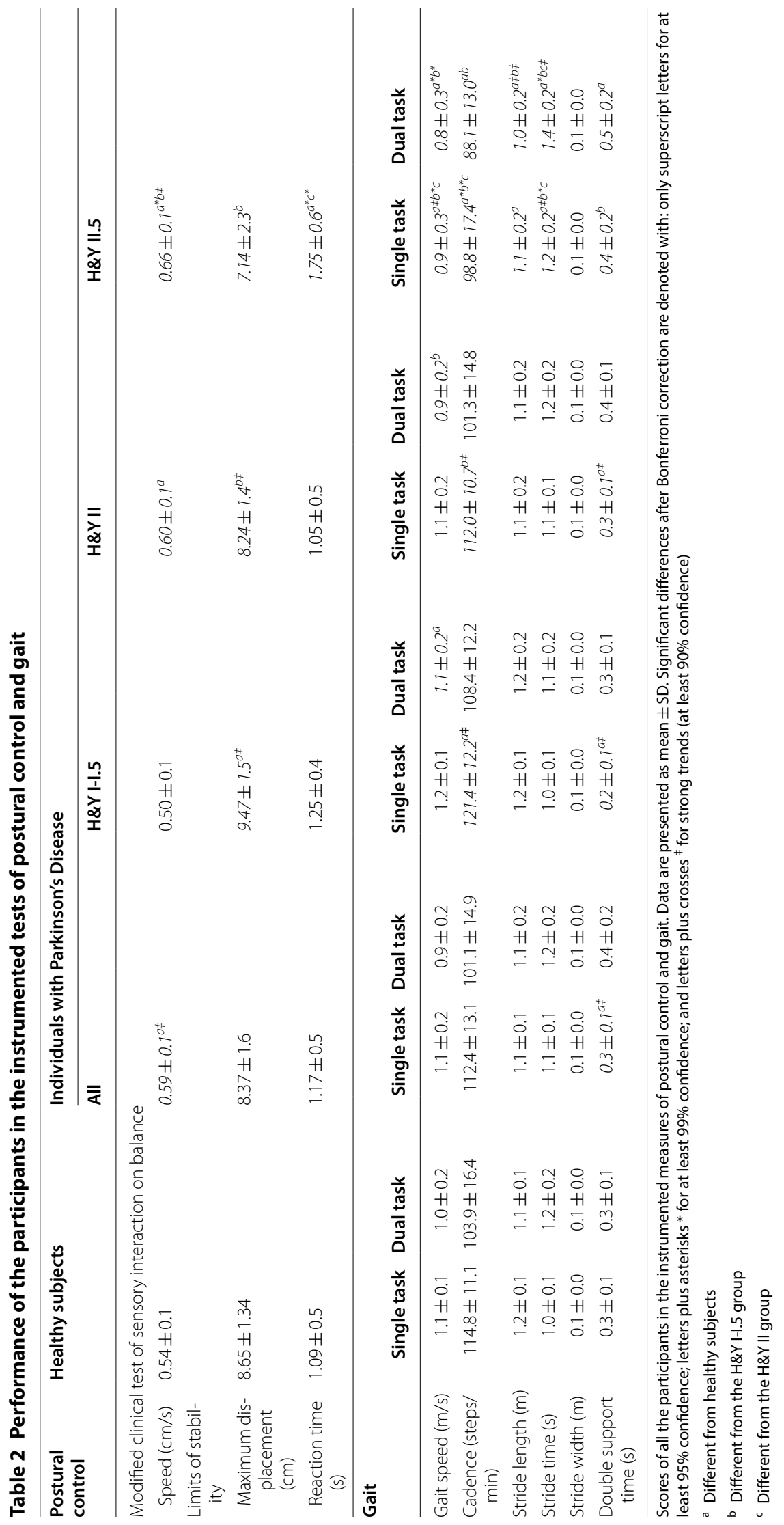


Table 3 Convergent validity between instrumented measures and conventional scales

\begin{tabular}{|c|c|c|c|c|c|}
\hline & \multicolumn{3}{|c|}{ Tinetti Performance Oriented Mobility Assessment } & \multirow{2}{*}{$\begin{array}{l}\text { Functional Gait } \\
\text { Assessment }\end{array}$} & \multirow[t]{2}{*}{ 10-m Walking Test } \\
\hline & Total & Balance & Gait & & \\
\hline \multicolumn{6}{|l|}{ Postural control } \\
\hline \multicolumn{6}{|c|}{ Modified clinical test of sensory interaction on balance } \\
\hline Speed & -.183 & -.24 & -.088 & -.154 & .13 \\
\hline \multicolumn{6}{|l|}{ Limits of stability } \\
\hline Maximum displacement & $.484^{* *}$ & $.413^{* *}$ & $.455^{* *}$ & $.516^{* *}$ & $-.506^{* *}$ \\
\hline Reaction time & $-.354^{* *}$ & $-.369^{* *}$ & -0.265 & $-.501^{* *}$ & $279^{*}$ \\
\hline \multicolumn{6}{|l|}{ Gait (single-task) } \\
\hline Gait speed & $.521^{* *}$ & $.509^{* *}$ & $.422^{* *}$ & $.766^{* *}$ & $-.850^{* *}$ \\
\hline Cadence & $.447^{* *}$ & $.434^{* *}$ & $.364^{* *}$ & $.594^{* *}$ & $-.698^{* *}$ \\
\hline Stride length & $.385^{* *}$ & $.360^{* *}$ & $.329^{*}$ & $.594^{* *}$ & $-.655^{* *}$ \\
\hline Stride time & $-.458^{* *}$ & $-.455^{* *}$ & $-.363^{* *}$ & $-.645^{* *}$ & $.750^{* *}$ \\
\hline Stride width & -.026 & .042 & .09 & -.011 & .059 \\
\hline Step length & $.293^{*}$ & $.327^{*}$ & .196 & $.541^{* *}$ & $-.625^{* *}$ \\
\hline Step time & $-.458^{* *}$ & $-.414^{* *}$ & $-.405^{* *}$ & $-.628^{* *}$ & $.732^{* *}$ \\
\hline Double support time & $-.475^{* *}$ & $-.458^{* *}$ & $-.391^{* *}$ & $-.592^{* *}$ & $.761^{* *}$ \\
\hline
\end{tabular}

Correlations between measures of the instrumented tests and conventional clinical scales

${ }^{*} \mathrm{p}<0.05$. ${ }^{* *} \mathrm{p}<0.01$

this study between individuals classified as H\&Y I-I.5 and those in other stages may be due to the abnormal performance of the H\&Y I-I.5 group in this study, which was improved even compared with healthy controls.

Instrumented gait assessment using the Kinect v2 successfully differentiated H\&Y II.5-stage PD participants from healthy controls during both single and dual-task conditions for all gait parameters, except stride width. As previously reported [6], walking parameters deteriorated during the dual-task condition in this study. The negative effects of dual-tasking were evident for both healthy controls and individuals with PD, for all gait parameters, except stride width. The absence of changes in stride width during both conditions is supported by a previous study, which reported comparable results among individuals with $\mathrm{PD}$, both with and without cognitive impairments [52]. The additional cognitive demands of the dual-task condition had a larger effect on PD patients in comparison to healthy subjects, which is also consistent with previous reports $[53,54]$. The observed enhancement of gait disturbances during the dual-task condition has been explained as a consequence of the activation of parallel processes in frontal attentional areas, which interferes with basal gait commands [55]. Such interference could be less pronounced during the early stages of $\mathrm{PD}$ when cognition is generally well-enough preserved to over-compensate for this attentional interference $[56,57]$. All these results under the dual-task condition should be taken into account considering that parameters of singletask walking have been reported to be more accurate and have less variability for predicting the progression of the pathology [58].

The performances of H\&Y I-I.5 PD patients observed in our study are comparable to those reported in previous studies [22, 59]. Other studies have reported a lack of significant balance or gait alterations during the early stages of PD [3, 59], which may indicate the development of compensatory mechanisms during the early stages of pathology. This abnormal performance could be also explained by the Hawthorne effect, which describes how a subject's awareness of being observed can motivate an improved performance [60]. Specific analysis of other gait features could have improved the sensitive of the Kinect v2 to the motor differences among early stages of PD. First, reduced arm swing has been identified as a clinical feature of early stages of PD that can be evidenced using instruments, such as inertial sensors [61] and even with the Kinect [62]. Second, dynamic postural control during turning has been also shown to be altered even in the early stages of PD, which can be evidenced with a motion analysis system [63]. Third, subjects in early stages of PD can also have difficulties to maintain a steady gait rhythm, which can manifest as an increased stride-tostride variability [5, 64]. Future studies should investigate the ability of the Kinect v2 to detect these motor features in early stages of PD, which might be even motor markers of prodromal PD [61]. A few studies have identified differences in gait performance between individuals with the AR phenotype and those with other phenotypes, such as decreased speed and stride compared with those with 
the TD phenotype [4]. Slower speeds and shorter step lengths have been also described in subjects who present with the freezing of gait, which is more prevalent for the AR phenotype $[65,66]$, compared with healthy controls [5]. Our study suggests that patients with the AR phenotype show slightly more impaired balance and increased gait disturbances compared with patients with other phenotypes. The limited number of participants with an AR phenotype included in this study may have impaired the ability to observe significant differences among phenotypes.

The convergent validity of the instrumented postural and gait assessments with conventional clinical tools in this study was comparable not only to that of the clinical tools used [67] but also to that of laboratory-grade and gold-standard systems [68,69]. More importantly, the assessments made by the instrumented tests were consistent (that is, had the same correlation sign) with those made using clinical scales. For instance, increased sway was associated with an increased time necessary to perform the 10-m Walking Test, and lower scores in the Tinetti Performance Oriented Mobility Assessment and the Functional Gait Assessment.

The ability detect the dependence of posture and gait performance on demographic variables, the sensitivity to discriminate between healthy controls and individuals during the middle stages of pathology, and the convergent validity with clinical scales support the usefulness of these low-cost instrumented tools as complements to the clinical assessment of postural control and gait in PD patients. These results, together with the low-cost and portability of the tested devices, could also support their use as a low-cost alternative to laboratory-grade systems in the clinical setting, to complement postural and gait assessments. Despite their widespread availability, it is important to consider that these devices have been discontinued and, consequently, future studies should investigate the feasibility of using the latest generation of low-cost cameras, such as the Azure Kinect (Microsoft, Redmond, WA, USA), and deep learning algorithms of computer vision to assess human posture and gait.

\section{Conclusions}

In summary, the instrumented assessment of postural control and gait in individuals with PD, using low-cost devices, may provide feasible and complementary information to conventional measures that are used to diagnose and monitor pathological progression.

\section{Authors' contributions}

$R L$, PP, and IA conceived and designed the study. RL and $J L$ designed the instrumented posturography and gait test. Data acquisition and analysis was done by IA, JL, MA, and PP. All authors read and approved the final manuscript.

\section{Funding}

This study has been funded by project VALORA, Grant 201701-10 of the Fundació la Marató de la TV3 (Barcelona, Spain) and the European Union through the Operational Program of the European Regional Development Fund (ERDF) of the Valencian Community 2014-2020 (IDIFEDER/2018/029) to RL, and Alter Laboratories SA to PP.

\section{Availability of data and materials}

The datasets used and/or analysed during the current study are available from the corresponding author on reasonable request.

\section{Ethics approval and consent to participate}

The Institutional Review Board of University Hospital Mútua de Terrassa approved all the procedures. Written informed consent was obtained from all the participants.

\section{Consent for publication}

Not applicable.

\section{Competing interests}

The authors declare that they have no competing interests.

\section{Author details}

1 Fundació Docència i Recerca Mútua de Terrassa, Terrassa, Barcelona, Spain. ${ }^{2}$ Movement disorders Unit, Department of Neurology, Memory Disorders Unit, Hospital Universitari Mútua de Terrassa, Terrassa, Barcelona, Spain. ${ }^{3}$ Neurorehabilitation and Brain Research Group, Instituto Interuniversitario de Investigación en Bioingeniería, Universitat Politècnica de València, Ciudad Politécnica de la Innovación-Building 8B-Access M-Floor 0, Camino de Vera s/n, 46022 Valencia, Spain. ${ }^{4}$ NEURORHB. Servicio de Neurorrehabilitación de Hospitales Vithas, Río Tajo 1, 46011 Valencia, Spain.

Received: 2 April 2020 Accepted: 7 October 2020

Published online: 11 November 2020

\section{References}

1. Nussbaum RL, Ellis CE. Alzheimer's Disease and Parkinson's Disease. N Engl J Med. 2003;13:56-64.

2. Hass CJ, Malczak P, Nocera J, Stegemöller EL, Shukala A, Malaty I, et al. Quantitative normative Gait data in a large cohort of ambulatory persons with parkinson's disease. PLoS ONE. 2012;2:12.

3. Hass CJ, Bishop M, Moscovich M, Stegemöller EL, Skinner J, Malaty IA, et al. Defining the clinically meaningful difference in gait speed in persons with Parkinson disease. J Neurol Phys Ther. 2014;38:233-8.

4. Koh S, Park K, Lee D. Gait analysis in patients with Parkinson 's disease: relationship to clinical features and freezing. J Mov Disord. 2008;1:6.

5. Nanhoe-Mahabier W, Snijders AH, Delval A, Weerdesteyn V, Duysens J, Overeem S, et al. Walking patterns in Parkinson's disease with and without freezing of gait. Neuroscience. 2011;182:217-24. https://doi. org/10.1016/j.neuroscience.2011.02.061.

6. Raffegeau TE, Krehbiel LM, Kang N, Thijs FJ, Altmann LJP, Cauraugh JH, et al. A meta-analysis: Parkinson's disease and dual-task walking. Park Relat Disord. 2019;62:28-35.

7. Panyakaew P, Bhidayasiri R. The spectrum of preclinical gait disorders in early Parkinson's disease: Subclinical gait abnormalities and compensatory mechanisms revealed with dual tasking. J Neural Transm. 2013;120:1665-72.

8. Bloem BR, Marinus J, Almeida Q, Dibble L, Nieuwboer A, Post B, et al. Measurement instruments to assess posture, gait, and balance in Parkinson's disease: Critique and recommendations. Mov Disord. 2016:31:1342-55.

9. Delval A, Snijders AH, Weerdesteyn V, Duysens JE, Defebvre L, Giladi N, et al. Objective detection of subtle freezing of gait episodes in Parkinson's disease. Mov Disord. 2010;25:1684-93. https://doi.org/10.1002/ mds.23159.

10. Verghese J, Holtzer R, Lipton RB, Wang C. Quantitative gait markers and incident fall risk in older adults. J Gerontol Ser A Biol Sci Med Sci. 2009;64A:896-901. 
11. Schlachetzki JCM, Barth J, Marxreiter F, Gossler J, Kohl Z, Reinfelder S, et al. Wearable sensors objectively measure gait parameters in Parkinson's disease. PLOS ONE. 2017;12:1-18.

12. Godinho C, Domingos J, Cunha G, Santos AT, Fernandes RM, Abreu D, et al. A systematic review of the characteristics and validity of monitoring technologies to assess Parkinson's disease. J Neuroeng Rehabil. 2016:13:1-10. https://doi.org/10.1186/s12984-016-0136-7.

13. Micó-Amigo ME, Kingma I, Faber GS, Kunikoshi A, van Uem JMT, van Lummel RC, et al. Is the assessment of 5 meters of gait with a single body-fixed-sensor enough to recognize idiopathic Parkinson's diseaseassociated gait? Ann Biomed Eng. 2017;45:1266-78.

14. Rovini E, Maremmani C, Cavallo F. How wearable sensors can support parkinson's disease diagnosis and treatment: a systematic review. Front Neurosci. 2017:9:12.

15. Chen S, Lach J, Lo B, Yang GZ. Toward Pervasive Gait Analysis With Wearable Sensors: A Systematic Review. IEEE J Biomed Health Inform. 2016;9:1521-37.

16. Díaz S, Stephenson JB, Labrador MA. Use of wearable sensor technology in gait, balance, and range of motion analysis. Appl Sci. 2020;10(1):234

17. Park DS, Lee G. Validity and reliability of balance assessment software using the Nintendo Wii balance board: usability and validation. J Neuroeng Rehabil. 2014;11:99.

18. Holmes JD, Jenkins ME, Johnson AM, Hunt MA, Clark RA. Validity of the Nintendo Wii balance board for the assessment of standing balance in Parkinson's disease. Clin Rehabil. 2013;27:361-6.

19. Llorens R, Latorre J, Noé E, Keshner EA. Posturography using the Wii Balance BoardTM. A feasibility study with healthy adults and adults poststroke. Gait Posture. 2016;43:228-32.

20. Bower KJ, McGinley JL, Miller KJ, Clark RA. Instrumented static and dynamic balance assessment after stroke using Wii Balance Boards: Reliability and association with clinical tests. PLOS ONE. 2014:9:32321.

21. Eltoukhy M, Kuenze C, Andersen MS, Oh J, Signorile J. Prediction of ground reaction forces for Parkinson's disease patients using a kinect-driven musculoskeletal gait analysis model. Med Eng Phys. 2017:50:75-82

22. Eltoukhy M, Kuenze C, Oh J, Jacopetti M, Wooten S, Signorile J. Microsoft Kinect can distinguish differences in over-ground gait between older persons with and without Parkinson's disease. Med Eng Phys. 2017:44:1-7.

23. Dolatabadi E, Taati B, Mihailidis A. Concurrent validity of the Microsoft Kinect for Windows $\mathrm{V} 2$ for measuring spatiotemporal gait parameters. Med Eng Phys. 2016;38:952-8.

24. Mentiplay BF, Perraton LG, Bower KJ, Pua YH, McGaw R, Heywood S, et al. Gait assessment using the Microsoft Xbox One Kinect: Concurrent validity and inter-day reliability of spatiotemporal and kinematic variables. J Biomech. 2015;48:2166-70.

25. Cao Y, Li BZ, Li QN, Xie JD, Cao BZ, Yu SY. Kinect-based gait analyses of patients with Parkinson's disease, patients with stroke with hemiplegia, and healthy adults. CNS Neurosci Ther. 2017;9:447-9.

26. Galna B, Barry G, Jackson D, Mhiripiri D, Olivier P, Rochester L. Accuracy of the Microsoft Kinect sensor for measuring movement in people with Parkinson's disease. Gait Posture. 2014;39:1062-8.

27. Hughes AJ, Daniel SE, Kilford L, Lees AJ. Accuracy of clinical diagnosis of idiopathic Parkinson's disease: a clinico-pathological study of 100 cases. J Neurol Neurosurg Psychiatry. 1992;55:181-4.

28. Goetz CG, Poewe W, Rascol O, Sampaio C, Stebbins GT, Counsell C, et al. Movement Disorder Society Task Force report on the Hoehn and Yahr staging scale: status and recommendations. Mov Disord. 2004;19:1020-8.

29. Escribano-Aparicio MV, Pérez-Dively M, García-García FJ, Pérez-Martín A, Romero L, Ferrer G, et al. Validación del MMSE de Folstein en una población española de bajo nivel educativo1. Rev Esp Geriatr Gerontol. 1999;34:319-26.

30. Latorre J, Colomer C, Alcañiz M, Llorens R. Gait analysis with the Kinect v2: Normative study with healthy individuals and comprehensive study of its sensitivity, validity, and reliability in individuals with stroke. J Neuroeng Rehabil. 2019;16:12.

31. Eltoukhy M, Oh J, Kuenze C, Signorile J. Improved kinect-based spatiotemporal and kinematic treadmill gait assessment. Gait Posture. 2017;51:77-83. https://doi.org/10.1016/j.gaitpost.2016.10.001.

32. Rajput AH, Voll A, Rajput ML, Robinson CA, Rajput A. Course in parkinson disease subtypes: a 39-year clinicopathologic study. Neurology. 2009;73:206-12.
33. Rajput AH, Sitte HH, Rajput A, Fenton ME, Pifl C, Hornykiewicz O. Globus pallidus dopamine and Parkinson motor subtypes: Clinical and brain biochemical correlation. Neurology. 2008;70(16 Pt 2):1403-10.

34. Fahn S. Unified Parkinson's disease rating scale. Recent Dev Park Dis. 1987;2:153-64

35. Kaufer DI, Cummings JL, Ketchel P, Smith V, MacMillan A, Shelley T, et al. Validation of the NPI-Q, a Brief Clinical Form of the Neuropsychiatric Inventory. J Neuropsychiatry Clin Neurosci. 2000;12:233-9. https://doi. org/10.1176/jnp.12.2.233.

36. Chaudhuri KR, Martinez-Martin P, Brown RG, Sethi K, Stocchi F, Odin P, et al. The metric properties of a novel non-motor symptoms scale for Parkinson's disease: results from an international pilot study. Mov Disord. 2007;22:1901-11.

37. Christenson GA, Faber RJ, De Zwaan M, Raymond NC, Specker SM, Ekern $M D$, et al. Compulsive buying: descriptive characteristics and psychiatric comorbidity. J Clin Psychiatry. 1994;55:5-11.

38. Peto V, Jenkinson C, Fitzpatrick R, Greenhall R. The development and validation of a short measure of functioning and well being for individuals with Parkinson's disease. Qual life Res. 1995;4:241-8.

39. Lang JT, Kassan TO, Devaney LL, Colon-Semenza C, Joseph MF. Test-retest reliability and minimal detectable change for the 10-meter walk test in older adults with Parkinson's disease. J Geriatr Phys Ther. 2016;39:165-70.

40. Woodhull-McNeal AP. Changes in posture and balance with age. Aging Clin Exp Res. 1992;4:219-25.

41. Terrier P, Reynard F. Effect of age on the variability and stability of gait: a cross-sectional treadmill study in healthy individuals between 20 and 69 years of age. Gait Posture. 2015;41:170-4.

42. Bohannon RW, Williams AA. Normal walking speed: A descriptive metaanalysis. Physiotherapy. 2011:97:182-9.

43. Elbaz A, Artaud F, Dugravot A, Tzourio C, Singh-Manoux A. The gait speed advantage of taller stature is lost with age. Sci Rep. 2018;8:12.

44. Laroche DP, Marques NR, Shumila HN, Logan CR, Laurent RS, Goncąlves $M$. Excess body weight and gait influence energy cost of walking in older adults. Med Sci Sports Exerc. 2015;47:1017-25.

45. Stylianou AP, McVey MA, Lyons KE, Pahwa R, Luchies CW. Postural sway in patients with mild to moderate parkinson's disease. Int J Neurosci. 2011;121:614-21.

46. Mancini M, Horak FB, Zampieri C, Carlson-Kuhta P, Nutt JG, Chiari L. Trunk accelerometry reveals postural instability in untreated Parkinson's disease. Park Relat Disord. 2011;17:557-62.

47. Morris M, lansek R, Smithson F, Huxham F. Postural instability in Parkinson's disease: a comparison with and without a concurrent task. Gait Posture. 2000;12:205-16.

48. Schoneburg B, Mancini M, Horak F, Nutt JG. Framework for understanding balance dysfunction in Parkinson's disease. Mov Disord. 2013;89:1474-82.

49. Doná F, Aquino CC, Gazzola JM, Borges V, Silva SMCA, Ganança FF, et al. Changes in postural control in patients with Parkinson's disease: a posturographic study. Physiother. 2016;102:272-9.

50. Rossi M, Soto A, Santos S, Sesar A, Labella T. A Prospective Study of Alterations in Balance among Patients with Parkinson's Protocol of the Postural Evaluation. Eur Neurol. 2009;11:171-6.

51. Ganesan M, Kumar P, Gupta A, Sathyaprabha TN. Dynamic posturography in evaluation of balance in patients of Parkinson 's disease with normal pull test : Concept of a diagonal pull test q. Park Relat Disord. 2010;16:595-9. https://doi.org/10.1016/j.parkreldis.2010.08.005.

52. Kim SM, Kim DH, Yang Y, Ha SW, Han JH. Gait Patterns in Parkinson's Disease with or without Cognitive Impairment. Dement Neurocognitive Disord. 2018;17:57.

53. Galletly R, Brauer SG. Does the type of concurrent task affect preferred and cued gait in people with Parkinson's disease? Aust J Physiother. 2005;51:175-80.

54. O'Shea S, Morris ME, lansek R. Dual task interference during gait in people with Parkinson disease: effects of motor versus cognitive secondary tasks. Phys Ther. 2002;82:888-97.

55. Penko AL, Streicher MC, Koop MM, Dey T, Rosenfeldt AB, Bazyk AS, et al. Dual-task interference disrupts parkinson's gait across multiple cognitive domains. Neuroscience. 2018;379:375-82.

56. Yogev-seligmann G, Hausdorff JM, Giladi N. The role of executive function and attention in gait. Mov Disord. 2008;23:329-42.

57. Giladi GYN. The contribution of postural control and bilateral coordination to the impact of dual tasking on gait. Exp Brain Res. 2013;226:81-93. 
58. Micó-Amigo ME, Kingma I, Heinzel S, Nussbaum S, Heger T, van Lummel $\mathrm{RC}$, et al. Dual vs single tasking during circular walking: what better reflects progression in Parkinson's disease? Front Neurol. 2019. https://doi. org/10.3389/fneur.2019.00372/full.

59. Duncan RP, Combs-Miller SA, McNeely ME, Leddy AL, Cavanaugh JT, Dibble LE, et al. Are the average gait speeds during the 10 meter and 6 minute walk tests redundant in Parkinson disease? Gait Posture. 2017;52:178-82.

60. Robles-García V, Corral-Bergantiños Y, Espinosa N, Jácome MA, GarcíaSancho C, Cudeiro J, et al. Spatiotemporal gait patterns during overt and covert evaluation in patients with Parkinson's disease and healthy subjects: Is there a Hawthorne effect? J Appl Biomech. 2015;31:189-94.

61. Mirelman A, Bernad-Elazari H, Thaler A, Giladi-Yacobi E, Gurevich T, Gana-Weisz M, et al. Arm swing as a potential new prodromal marker of Parkinson's disease. Mov Disord. 2016;31:1527-34.

62. Ospina BM, Chaparro JAV, Paredes JDA, Pino YJC, Navarro A, Orozco JL. Objective arm swing analysis in early-stage Parkinson's disease using an RGB-D Camera (Kinect ${ }^{\circledR}$ ). J Parkinsons Dis. 2018;8:563-70.

63. Song J, Sigward S, Fisher B, Salem GJ. Altered dynamic postural control during step turning in persons with early-stage Parkinson's disease. Parkinsons Dis. 2012. https://doi.org/10.1155/2012/386962.

64. Hausdorff JM, Cudkowicz ME, Firtion R, Wei JY, Goldberger AL. Gait variability and basal ganglia disorders: Stride-to-stride variations of gait cycle timing in Parkinson's disease and Huntington's disease. Mov Disord. 1998;13:428-37.

65. Lamberti P, Armenise S, Castaldo V, De Mari M, Iliceto G, Tronci P, et al. Freezing gait in parkinson's disease. Eur Neurol. 1997;38:297-301.

66. Thenganatt MA, Jankovic J. Parkinson disease subtypes JAMA Neurol. 2014;71:499-504.

67. Lin J-H, Hsu M-J, Hsu H-W, Wu H-C, Hsieh C-L. Psychometric comparisons of 3 functional ambulation measures for patients with stroke. Stroke. 2010;41:2021-5.

68. McDonough AL, Batavia M, Chen FC, Kwon S, Ziai J. The validity and reliability of the GAITRite system's measurements: A preliminary evaluation. Arch Phys Med Rehabil. 2001;82:419-25.

69. Greenberg M, Gronley J, Perry J, Lawthwaite R. Concurrent validity of observational gait analysis using the vicon motion analysis system. Gait Posture. 1996;4:167-8.

\section{Publisher's Note}

Springer Nature remains neutral with regard to jurisdictional claims in published maps and institutional affiliations.
Ready to submit your research? Choose BMC and benefit from:

- fast, convenient online submission

- thorough peer review by experienced researchers in your field

- rapid publication on acceptance

- support for research data, including large and complex data types

- gold Open Access which fosters wider collaboration and increased citations

- maximum visibility for your research: over 100M website views per year

At BMC, research is always in progress.

Learn more biomedcentral.com/submissions 